\title{
CASE SERIES OF FOUR QUADRANT PARALLEL PERIPHERAL SCREW FIXATIONS FOR FRACTURED NECK OF FEMUR AND THEIR OUTCOME
}

\author{
Palaniappan Mathivanan ${ }^{1}$, Ganesan Ramesh Prabu², Anbu Srinivasan ${ }^{3}$
}

${ }_{1}^{1}$ Professor, Department of Orthopaedics, KAP Viswanatham Government Medical College/MGM Government Hospital, Trichy. ${ }^{2}$ Assistant Professor, Department of Orthopaedics, KAP Viswanatham Government Medical College/MGM Government Hospital, Trichy. ${ }^{3}$ Associate Professor, Department of Orthopaedics, KAP Viswanatham Government Medical College/MGM Government Hospital, Trichy.

\section{ABSTRACT}

\section{BACKGROUND}

Femoral neck fractures are usually observed in the elderly population after a simple fall or minor trauma. In contrast, in young adults, femoral neck fractures are uncommon and are often due to high energy trauma caused by road traffic injuries, work injuries, or fall from a height. The surgical management of femoral neck fractures comprises various options:

a) Closed or open reduction with internal fixation of the fracture with screw fixation, b) hemiarthroplasty and c) total hip arthroplasty. Selection of the mode of treatment depends on the patient's age, level of activity, medical comorbidities, degree of bone density, and degree of displacement of the femoral head. We hereby present results of a modified screw fixation technique (Four Quadrant Parallel Peripheral Screw Fixation) in femoral neck fractures of both young and old patients.

\section{MATERIALS AND METHODS}

Fifty patients aged 35 - 70 years with fractured neck of femur and operated in our hospital were included in this study. They were treated with closed reduction under image intensifier control and fixed with four quadrant parallel peripheral cannulated cancellous screws. Functional and Radiological results were evaluated periodically.

\section{RESULTS}

The functional outcome was evaluated with a new six-point functional hip score advocated by Satish et al. Radiologically fracture united within 3 months period of time. Out of 50 patients, two patients had developed osteonecrosis. They were treated by screw removal and converted to Hemiarthroplasty.

\section{CONCLUSION}

The four quadrant parallel peripheral (FQPP) screw fixation technique, allows controlled collapse, gives good stability, and avoids fixation failure and good bone healing in femoral neck fracture in patient's $\geq 35$ years of age.

\section{KEYWORDS}

Femoral Neck Fracture, Four Quadrant Parallel Screw Fixation, Hemiarthroplasty, Avascular Necrosis.

HOW TO CITE THIS ARTICLE: Mathivanan P, Prabu GR, Srinivasan A. Case series of four quadrant parallel peripheral screw fixations for fractured neck of femur and their outcome. J. Evolution Med. Dent. Sci. 2017;6(44):3404-3410, DOI: $10.14260 /$ Jemds/2017/738

\section{BACKGROUND}

Femoral Neck Fractures (FNF) is commonly observed in the elderly population after a simple fall or minor trauma. ${ }^{1}$ In contrast, in young adults, FNFs are uncommon and are mainly due to road traffic injuries or fall from a height.2, 3 Most of the FNF patients are over 65 years old with poor bone quality and progressive osteoporosis.

The classification of femoral neck fractures is based on the degree of displacement. Most are sub-capital intraarticular fractures. But FNFs also occur in young adults creating a nightmare for the treating orthopaedic surgeon. There are two main classification systems used for management and prognosis of fractured neck of femur namely, Pauwel's and Garden.

Financial or Other, Competing Interest: None.

Submission 31-03-2017, Peer Review 18-05-2017,

Acceptance 25-05-2017, Published 01-06-2017.

Corresponding Author:

Dr. Ganesan Ramesh Prabu,

No. 5, Aishwarya Apartment,

$B 31,11^{\text {th }}$ Cross, Thillai Nagar,

Trichy-620018.

E-mail: grpsha@gmail.com

DOI: $10.14260 /$ jemds $/ 2017 / 738$
Pauwel's classification is based on the angle of femoral neck fracture relative to the horizontal axis. Garden's classification is based on the degree of displacement of the femoral head. The unstable fractures - namely Pauwel's type III or Garden's type III and IV - are seen in young adults more frequently; treating which is more difficult because of the instability, increased shear force, varus movement and because of these they have a higher risk of fixation failure, malunion, non-union and osteonecrosis. $4,5,6$

The treatment of intracapsular neck femur fracture has undergone many changes. Nowadays, the surgical treatment of femoral neck fracture consists of various options: a) Closed or Open Reduction with Internal Fixation of the fracture, b) Hemiarthroplasty, or c) Total Hip Arthroplasty.

Selection of treatment is based on the patient's age, activity level, status of bone quality, degree of displacement and associated comorbidity. Most surgeons prefer to treat non-displaced fractures (Garden's type I and II) in both young and elderly patients by internal fixation but prefer arthroplasty for displaced fractures (Garden's type III and IV) in patients above 80 years.

The current treatment scenario is that FNFs in patients below 60 years of age should be treated by internal fixation with screws and arthroplasty should be reserved for elderly patients above 80 years, but in 60 to 80 years old patients no 
single method of treatment has been able to achieve $100 \%$ result. The choice of treatment still remains a grey zone. ${ }^{7}$ When compared to the arthroplasty, surgical procedure, surgical duration, bleeding, need of blood transfusion, infection and immediate postoperative mortality are considerably less with internal fixation. ${ }^{8}$ Fixation failure and re-surgery are the disadvantages of internal fixation.

Many of the daily functional activities of Asian patients require squatting and sitting cross-legged, which cannot be performed with Arthroplasty; and thus, every effort of joint conservation should be aimed for. Fixation for FNFs is usually performed with cancellous screws or dynamic hip screw.

The controversial factors in cancellous screw fixation are: method of reduction - open or closed; number of screws used - two, three or four; the configuration of screws -parallel or non-parallel, vertical or triangular fashion; the positioning of screws in the head - centre of head or in the periphery and the addition of bone grafting - free fibula or quadratus femoris muscle pedicle grafting.

Most of the orthopaedic surgeons fixing fractured neck of femur use three screws in apex proximal triangular configuration. ${ }^{9,10}$ Sathish et al ${ }^{11}$ concluded that by adding the fourth screw and keeping the screws in peripheral portion of the head and neck, the area of fixation can be easily increased in FNFs fixation.

Ours being an institution for giving free treatment we always embrace techniques which are simple and replicable.
We also factor in better cost effective treatment. We found the technique published by Satish ${ }^{11}$ et al simple and quite easy to reproduce.

So we also followed the same technique and report the outcome of four quadrant parallel peripheral screw fixation technique in active, independent patients. This study is only a small step to solve the big problem with means and methods easily available to and by a very simple surgical procedure.

\section{MATERIALS AND METHODS}

This case series study was conducted from January 2012 to June 2016 at KAPV Government Medical College and MGM Hospital, Tiruchirapalli.

Fifty patients aged between 35 - 70 years with fractured neck of femur satisfying the inclusion criteria and operated in our hospital were included in the study. The Inclusion criteria for four quadrant cannulated screw fixation were:

Patients between ages of 35 to 70 years, All Garden's stage I to IV fractures, presence of primary compressive trabeculae in hip anteroposterior (AP) radiograph, independently mobile patient without neuromuscular disorder, no evidence of pathological fracture and without any metabolic bone disorder.

All patients underwent routine AP and lateral radiographs of the involved hip. Pauwel's angle and Garden's type were analysed for every fracture.

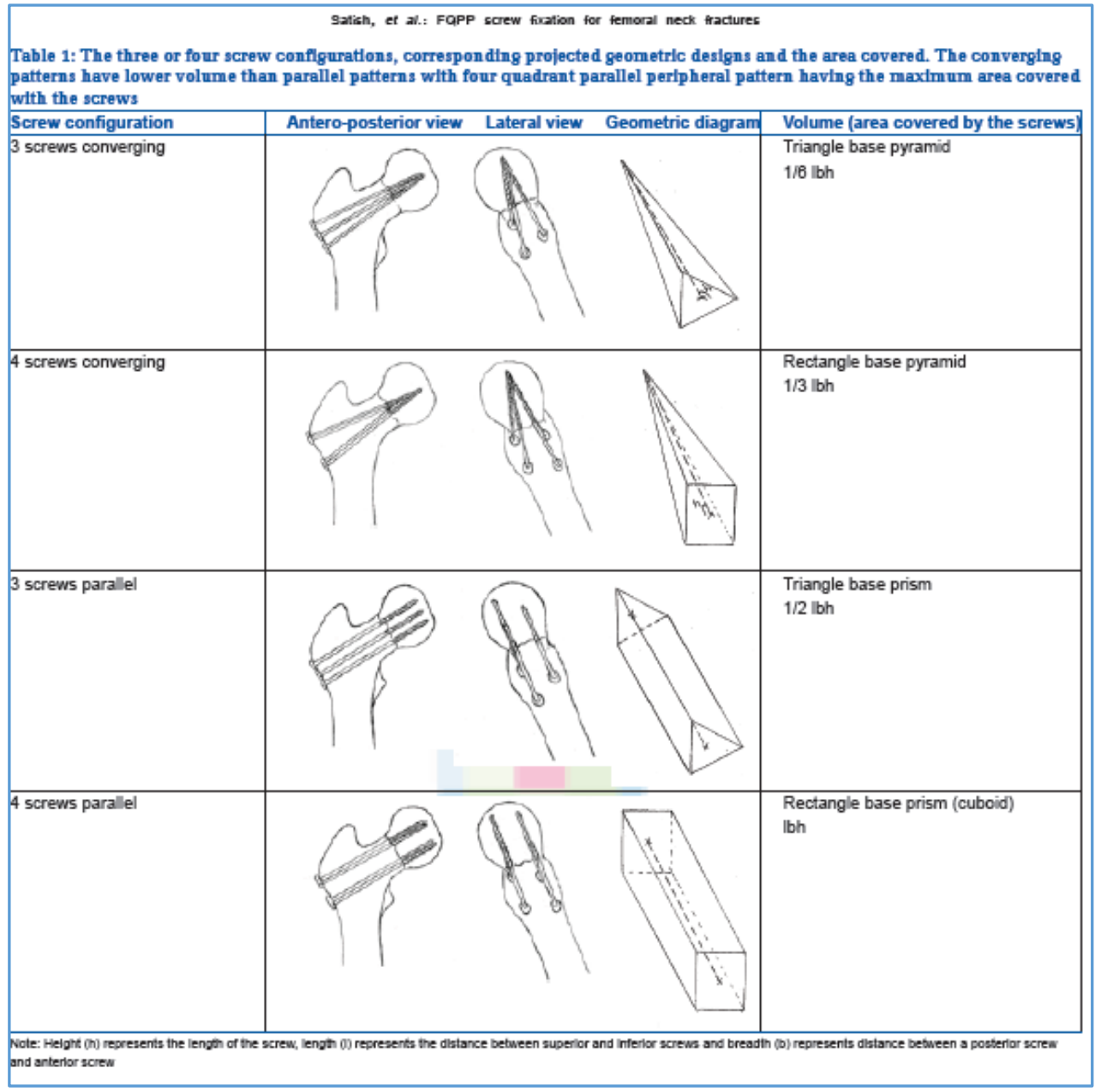

Figure 1. FQPP Screw Fixation Geometrical Area Covered (Reprinted from Satish et al13) 


\section{Surgical Procedure}

The patient is positioned on the fracture table with the contralateral leg flexed to 90 degrees, to allow full visualisation of the femoral neck and head on the lateral view. The injured leg is placed in moderate traction and slight internal rotation. Displaced fractures were reduced by traction on the injured limb in extension followed by internal rotation and abduction.

The patient is placed on the fracture table with the leg placed in traction and in a neutral position. ${ }^{12}$ The leg is gently internally rotated and slightly abducted, while viewing the reduction in the $\mathrm{AP}$ and lateral views on the imager. The Calcar cortex should align when the fragments are in anatomic position and the leg is fixed in this position. A cross sectional fracture contact area of $75 \%$ or more without coxa vara should be the aim of reduction.

Under image guidance a small incision ( 3 to $4 \mathrm{~cm}$ ) is made just distal to the lesser trochanter and the iliotibial band incised. The vastus lateral is reflected anteromedially and the bone surface visualised. The inferior screws were placed first. The starting point for the inferior screws was usually at the level of lesser trochanter. A pilot hole was made with $3.5 \mathrm{~mm}$ drill bit perpendicular to shaft surface in the exact needy location i.e., posterior to midlateral cortex at the level of lesser trochanter for inferior posterior (IP) screw.

The guide wire was pushed into the desired screw angled position: parallel and just superior to the inferior border of the neck in the anteroposterior view, parallel and just anterior to the posterior border of the neck in the lateral view. After positioning the guide wire in the desired position, the same was drilled into the head $5 \mathrm{~mm}$ below the articular margin. Tapping of the lateral cortex was done for screw entry in older patients and for younger patients tapping was done up to head.

A $6.5 \mathrm{~mm}$ diameter, $16 \mathrm{~mm}$ partially threaded screw of length measured through $\mathrm{C}$ arm is inserted and tightened. On tightening the screw, compression across the fracture site will be visible in the C-Arm images. Next will be the Inferior Anterior screw insertions. For this a pilot hole is made at the same level as of IP screw and anterior to the midlateral cortex of the femur. The guide wire is guided parallel to the IP screw in AP view and parallel and just posterior to the anterior cortex of the neck in lateral view.

The superior-posterior screw (SP) is inserted next. The entry for this is just below and parallel to the superior border of the neck in AP view and the position of the screw should be parallel to the IP screw in lateral view. The superior anterior screw was placed last keeping it parallel to the IA screw in the lateral view and parallel to SP screw in AP view.

This fixation technique is called Four Quadrant Parallel Peripheral (FQPP) fixation. This configuration is such that the four quadrants i.e. inferior-posterior, inferior-anterior, superior-posterior and superior-anterior quadrants are stabilised with distal fragment of trochanter and distal fragment of neck. The screws were placed as parallel as possible and as peripheral in the neck and head as possible. The screws should be in divergent pattern from neck into the head. The screws should never be in convergent fashion.

\section{Post-Operative Protocol}

The patient was given intravenous antibiotics till third postoperative day. Then, the patient was shifted to oral antibiotics. Third generation cephalosporins were generally used. The wound was inspected on second, fifth and eighth day. Sutures were removed on twelfth post-operative day.

\section{Mobilisation}

The patient was mobilised in bed after the postoperative pain had decreased. Patient was advised for opposite side turns in the bed in the immediate post-operative period, the patient was encouraged to do static quadriceps, terminal knee extension exercises. As soon as the patient gained the ability to do active assisted/active straight leg raise and the active abduction, patient was taken out of the bed roughly at about 5-10 days and non-weightbearing crutch walking was started.

After discharge from hospital, patients were followed up on OPD basis once in month for first 6 months and then once in two months till 1 year. Then, patients were called once in six months till 2 years. At each followup, clinical evaluation was done and mobilisation was assessed. AP and lateral Xrays of the hip were taken for radiological evaluation to know the occurrence of fracture union/non-union, rate of osteonecrosis and other complications.

\section{RESULTS}

\section{Age Distribution}

In our series, 41 patients (82\%) were below 60 years of age with an average age of 50 years (Table 1). Of 50 patients, 32 patients (64\%) were male and 18 patients (18\%) were female (Table 2).

\begin{tabular}{|c|c|c|}
\hline Age of the Patient & No. of the Patients & Percentage \\
\hline $30-39$ & 7 & $14 \%$ \\
\hline $40-49$ & 16 & $32 \%$ \\
\hline $50-59$ & 18 & $36 \%$ \\
\hline $60-70$ & 9 & $18 \%$ \\
\hline \multicolumn{3}{|c|}{ Table 1. Age Distribution } \\
\hline
\end{tabular}

\begin{tabular}{|c|c|c|}
\hline Sex of the Patient & No of Patients & Percentage \\
\hline Male & 32 & $64 \%$ \\
\hline Female & 18 & $36 \%$ \\
\hline Total & $\mathbf{5 0}$ & \\
\hline \multicolumn{2}{|c|}{ Table 2. Sex Ratio } \\
\hline
\end{tabular}

In our series out of 50 patients, 28 patients (56\%) had fracture of neck femur on the right side and 22 patients (44\%) had fracture on the left side (Table 3)

\begin{tabular}{|c|c|}
\hline Right & 28 \\
\hline Left & 22 \\
\hline Total & $\mathbf{5 0}$ \\
\hline \multicolumn{2}{|c|}{ Table 3. Side of the Fracture } \\
\hline
\end{tabular}

\begin{tabular}{|c|c|}
\hline Head injury & 2 \\
\hline Fractured Tibia & 3 \\
\hline Fractured clavicle & 2 \\
\hline Fractured distal radius & 3 \\
\hline Chest injury & 2 \\
\hline Total & $\mathbf{1 2}$ \\
\hline Table 4. Associated Injuries \\
\hline
\end{tabular}

Twelve patients $(24 \%)$ out of 50 patients in our series had associated injuries (Table 4). 


\begin{tabular}{|c|c|c|}
\hline Stage 1 & 7 & $14 \%$ \\
\hline Stage 2 & 20 & $40 \%$ \\
\hline Stage 3 & 15 & $30 \%$ \\
\hline Stage 4 & 8 & $16 \%$ \\
\hline Total & $\mathbf{5 0}$ & \\
\hline Table 5. Type of Fracture Based on Garden's Staging \\
\hline
\end{tabular}

In our series, 27 patients (54\%) had undisplaced fractures i.e. Garden's stage I and II, and 23 patients (56\%) had displaced fractures i.e. Garden's stage III and IV (Table 5). Radiological fracture union is defined as cortical union visible in 3 different cortices in two different radiological views.

Clinical union is defined as a union where the patient has no pain in performing his routine activities, mainly sitting cross-legged, squatting and returning to his normal duties which he performed before injury. Complete union is defined when radiological union and clinical union have been achieved.

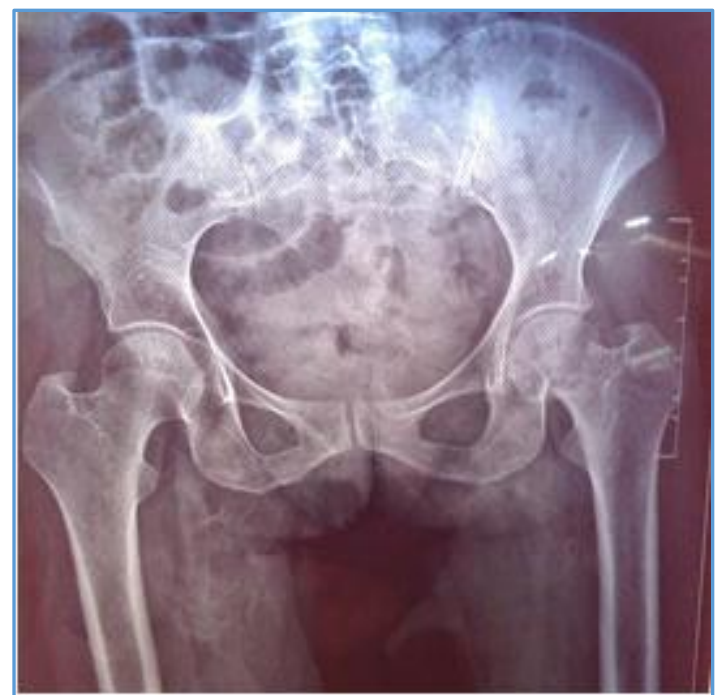

Figure 2. Case 1, Pre-op

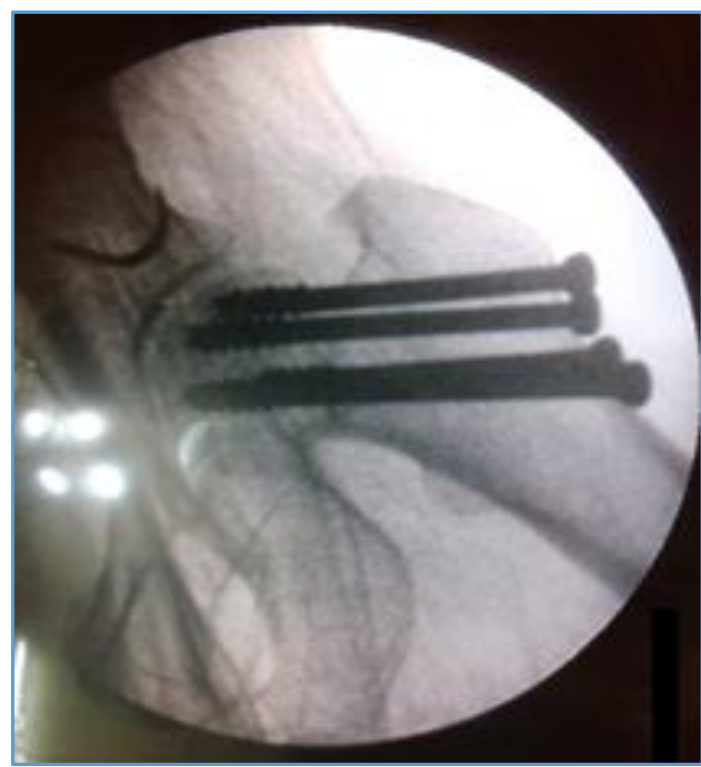

Figure 3. Intra-op C-arm Image

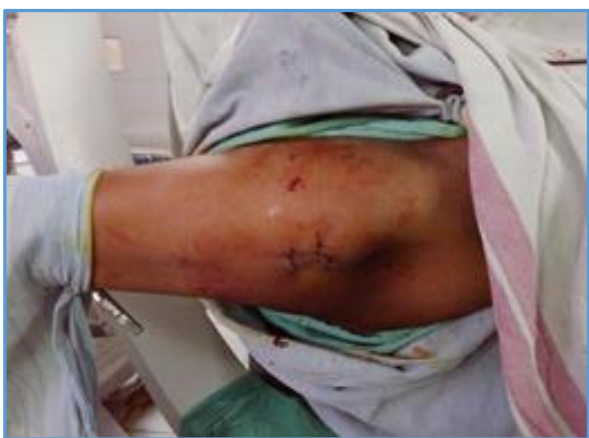

Figure 4. Clinical Image

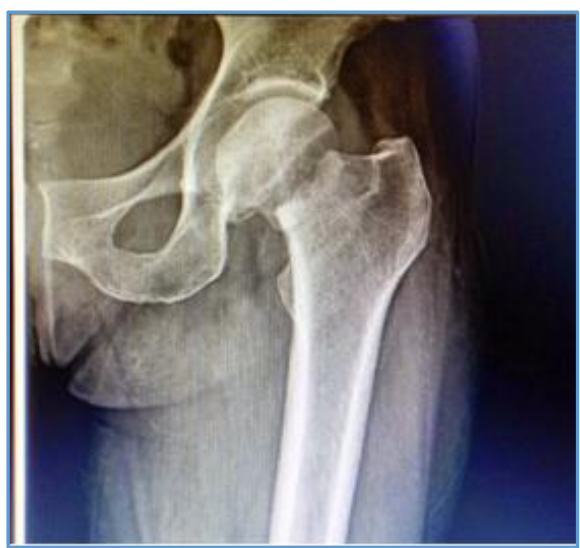

Figure 5. Case 2, Pre-op

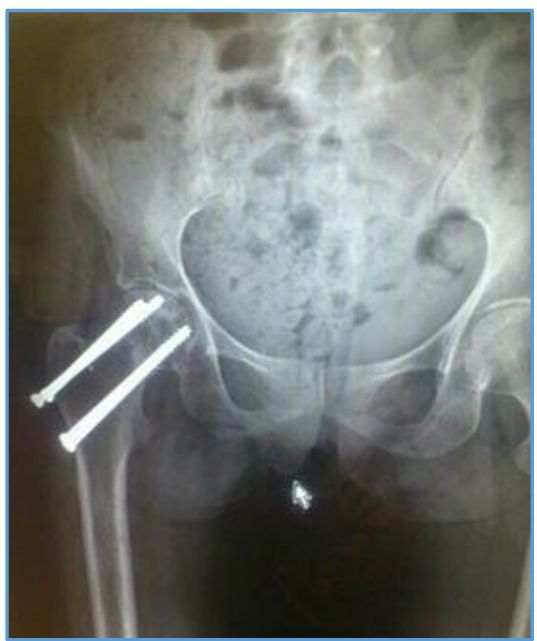

Figure 6. Post-op

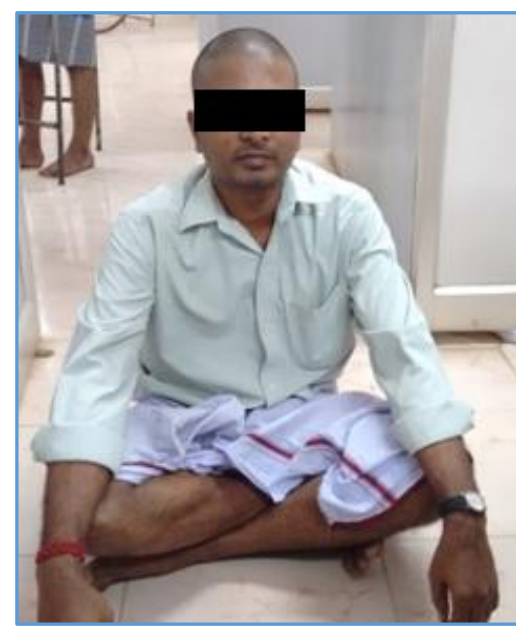

Figure 7. Clinical Photo at 6 Months 




Figure 8. Clinical Photo at 6 Months

\section{DISCUSSION}

Intracapsular fractures of the femoral neck can be treated with either immediate prosthetic replacement of the femoral head or internal fixation; however, prosthetic replacement is associated with a higher rate of morbidity and mortality than is internal fixation. ${ }^{13,14}$

Internal fixation is used to increase stability by compressing the fracture and then maintaining the reduction by neutralising forces acting on the hip. The fracture of the femoral neck is associated with injury to the blood supply of the femoral head. ${ }^{15}$ It is believed that revascularisation of the femoral head occurs after internal fixation. Most of the orthopaedic surgeons normally fix FNFs by using three screws in apex proximal triangular configuration.

In patients who underwent cannulated cancellous screw fixation for FNFs, six different types of screw configurations were found: Triangular configurations, consisting of two parallel screws with a third screw placed either superiorly, inferiorly, anteriorly or posteriorly; and linear configurations with two or three screws in a vertical line. ${ }^{16}$ The area covered by the fixation device is important in any fracture fixation; more the area on either side of fracture, better is the stability. By adding the fourth screw and keeping the screws in peripheral portion of the head and neck, the area of fixation can be easily increased in FNF fixation. This is called as Four Quadrant Parallel Peripheral Fixation (FQPPF).

Simple geometric projections and calculations revealed a dramatic increase in the volume occupied by the four peripheral screws compared to three screws (Figure 1). The FQPP construct gives better initial stability, allows better controlled collapse, improves stability with passing time and promotes fracture union.

These four screws are placed in the periphery and circumferential part of the neck; hence they act as four pillars and give excellent stability. We report the outcome of Four Quadrant Parallel Peripheral screw fixation technique in active, independent patients. FQPP fixation on comparison to that of regular three screw fixations has the following advantage; the good peripheral screw fixation does not allow the head to collapse in varus or any angulations. The disadvantages of three screw fixation are lack of parallelism between the three screws and the apex screw is not in the centre of two basal screws. ${ }^{17}$

This does not provide uniform load distribution across all areas of the femoral head. In FQPP construct, there is uniform load distribution across all areas of the femoral head and this helps in better fracture union.

The functional outcome was evaluated with a new sixpoint functional hip score advocated by Satish et $\mathrm{al}^{13}$ in their study (Table 6). This new hip clinical score is based on the clinical examination/observations or questions that we have asked and got answers from patients in every institutional visit.

Pain at the hip area, functional activity in the form of walking, stair climbing with support or without support, range of motion assessed in the form of sitting cross-legged in the floor and possible complete squatting or incomplete, and individual mobility outside the house were assessed.

We also noted that this scoring system was simple and easy to replicate and easy to carry out by any trained person.

\begin{tabular}{|c|c|c|c|c|}
\hline \multicolumn{5}{|c|}{ 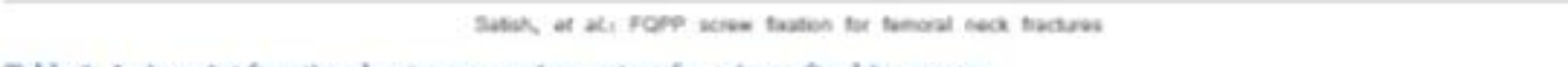 } \\
\hline Function & Score 0 & Scere 0.5 & Score 1 & Patient score \\
\hline Pain at hep area & Moderate or severe & and & No pain & \\
\hline Whasing & Signticant imp wet ad & Mad ime with aid & No and No Limp & \\
\hline Independent mobity outsibe the house & Not possicie & . & Possable & \\
\hline Setring cooss legoed in the floor & Not possicie & inconolete & Conviete & \\
\hline Souating & Not possitie & incomplete & Complete & \\
\hline Cinting stars & Not possetio & Usurg hand rals or seppont & Watwout any suspont & \\
\hline Total score & $=$ & * & $=$ & \\
\hline
\end{tabular}

Table 6. Six-point functional Outcome Scoring System (Reprinted from Satish et al ${ }^{13}$ )

Many of our patients come from rural background, where they do regular physical work even in advanced age. With healed fractured neck of femur, we can allow sitting in floor, squatting and advocate regular life style activity.

But, in case of replacement arthroplasty, prolonged medical supervision or followup is absolutely necessary. Hemiarthroplasty or total hip arthroplasty does not allow patient to sit cross-legged or squat which is almost a basic necessity for Asian Population. But FQPP fixation allows squatting and sitting cross-legged when the fracture heals.

If provided with choice of internal fixation, hemiarthroplasty or total hip arthroplasty, patients are more likely to choose screw fixation because of its ability to provide squatting and sitting cross-legged when fracture heals, especially in the age group between 50 to 70 years. This is one advantage. 
The other advantage with FQFF is that in case if the procedure fails and if it has to be revised, revising a failed FQPP screw fixation surgery into total hip arthroplasty is almost like a fresh hip surgery, but converting painful or failed hemiarthroplasty into THA is difficult because it is almost like a revision surgery and hence, the results obtained with revision THA on many occasions is almost always suboptimal.

Radiological union was seen within 3 months and complete union in 4 months in 38 patients, and in 10 other patients, radiological union was seen in 4 months and complete union in 6 months. Two patients had to be converted to hemiarthroplasty due to complications. Complications are usually manifold in FNF. In spite of near normal fixation, angular displacements, malunion and nonunion are commonly seen in FNF, and certain complications like AVN are very difficult to treat and often feared.

\section{Osteonecrosis}

Osteonecrosis is the main complication following Intracapsular fractures either with closed or open internal fixation. Osteonecrosis is diagnosed based on the assumption that if segmental collapse were to occur, it would be evident within two years. In our study out of 50 patients, two patients developed AVN changes within one year period followup. Both these patients had displaced fractures i.e. Garden's stage III and IV. Both these patients were the earliest to be operated in our series and the reduction techniques were not perfected during that time. Thus, out of 23 displaced fractures, we had 2 patients who developed osteonecrosis. These patients later underwent Hemiarthroplasty.

\section{Infection}

Since this procedure is carried out through a small incision, the chances of infection are very minimal. In our series, we had only 1 case of superficial infection. Infection was controlled by higher antibiotics.

\section{Screw Penetration}

One patient had painful hip with screw penetration in which osteonecrosis developed as well. We had to do screw removal and convert to primary Hemiarthroplasty.

The functional score was excellent in 38 hips (76\%), good in 10 hips (20\%) and poor in two hips (4\%).

The advantages of FQPP technique are: simple routine theatre setup, short surgical time and low expenditure, good functional outcome, small learning curve.

\section{CONCLUSION}

This FQPPF surgery for intracapsular fracture of neck femur is a very good method of treatment. There are several reasons for use of Four Quadrant Parallel Peripheral cannulated cancellous screw fixation, some include easy surgical procedure; smaller diameter guide pins can be used to determine the screw position and length accurately; parallel screws allow excellent compression to occur atraumatically by the lag effect of the screws.

In this series, we observed cannulated cancellous screw fixation represents a procedure with low operative mortality and morbidity and very high rate of fracture union.

With high healing rates, minimal complications and the availability of rescue surgery in the form of prosthetic replacement, this fixation should be attempted in all possible cases of femoral neck fractures.

\section{REFERENCES}

[1] Christodoulou NA, Dretakis EK. Significance of muscular disturbances in the localisation of fractures of the proximal femur. Clin Orthop Relat Res 1984;187:215-7.

[2] Swiontkowski MF, Winquist RA, Hansen ST. Fractures of the femoral neck in patients between the ages of twelve and forty-nine years. J Bone Joint Surg Am 1984;66(6):837-46.

[3] Robinson CM, Court-Brown CM, McQueen MM, et al. Hip fractures in adults younger than 50 years of age: epidemiology and results. Clin Orthop Relat Res 1995;312:238-46.

[4] Ly TV, Swiontkowski MF. Management of femoral neck fractures in young adults. Indian J Orthop 2008;42(1):3-12.

[5] van Embden D, Rhemrev SJ, Genelin F, et al. The reliability of a simplified Garden classification for intracapsular hip fractures. Orthop Traumatol Surg Res 2012;98(4):405-8.

[6] Pauyo T, Drager J, Albers A, et al. Management of femoral neck fractures in the young patient: a critical analysis review. World J Orthop 2014;5(3):204-17.

[7] Bhandari M, Devereaux PJ, Tornetta P, et al. Operative management of displaced femoral neck fractures in elderly patients. An international survey. J Bone Joint Surg Am 2005;87(9):2122-30.

[8] Heetveld MJ, Rogmark C, Frihagen F, et al. Internal fixation versus arthroplasty for displaced femoral neck fractures: what is the evidence? J Orthop Trauma 2009;23(6):395-402.

[9] Patwa JJ, Krishnan A, Pamecha CC. Biogeometry of femoral neck for implant placement. Indian J Orthop 2006;40(4):224-7.

[10] Huang HK, Su YP, Chen CM, et al. Displaced femoral neck fractures in young adults treated with closed reduction and internal fixation. Orthopedics 2010;33(12):873.

[11] Satish BR, Ranganadham AV, Ramalingam K, et al. Four quadrant parallel peripheral screw fixation for displaced femoral neck fractures in elderly patients. Indian J Orthop 2013;47(2):174-81.

[12] Whitman R. The abduction method: considered as the exponent of a treatment for all forms of fracture at the hip in accord with surgical principles. Am J Surg 1933;21(3):335-44.

[13] Eiskjaer, S, Ostgard SE. Risk factors influencing mortality after bipolar hemiarthroplasty in the treatment of fracture of the femoral neck. Clin Orthop Relat Res 1991;270:295-300.

[14] Garcia A, Neer CS, Ambrose GB. Displaced intracapsular fractures of the neck of the femur mortality and morbidity. J Trauma 1961;1:128-32.

[15] Catto M. A histological study of avascular necrosis of the femoral head after transcervical fracture. J Bone Joint Surg Br 1965;47(4):749-76. 
[16] Selvan VT, Oakley MJ, Rangan A, et al. Optimum configuration of cannulated hip screws for the fixation of intracapsular hip fractures: a biomechanical study. Injury 2004;35(2):136-41.
[17] Nordin M, Frankel VH. Biomechanics of bone. In: Nordin M, Frankel VH. eds. Basic biomechanics of the musculoskeletal system. Philadelphia: Lea and Febiger Co., 1989. 